PROCEEDINGS OF THE

AMERICAN MATHEMATICAL SOCIETY

Volume 135, Number 1, January 2007, Pages 99-106

S 0002-9939(06)08435-8

Article electronically published on June 13, 2006

\title{
A SUFFICIENT AND NECESSARY CONDITION FOR HALPERN-TYPE STRONG CONVERGENCE TO FIXED POINTS OF NONEXPANSIVE MAPPINGS
}

\author{
TOMONARI SUZUKI
}

(Communicated by Joseph A. Ball)

\begin{abstract}
In this paper, we prove a Halpern-type strong convergence theorem for nonexpansive mappings in a Banach space whose norm is uniformly Gâteaux differentiable. Also, we discuss the sufficient and necessary condition about this theorem. This is a partial answer of the problem raised by Reich in 1983.
\end{abstract}

\section{INTRODUCTION}

Let $C$ be a closed convex subset of a Banach space $E$. A mapping $T$ on $C$ is called a nonexpansive mapping if $\|T x-T y\| \leq\|x-y\|$ for all $x, y \in C$. We denote by $F(T)$ the set of fixed points of $T$. We know that $F(T)$ is nonempty in the case when $E$ is uniformly smooth and $C$ is bounded; see Baillon [1. See also [3, 4, 10, 13. and others. Fix $u \in C$. Then for each $t \in(0,1)$, there exists a unique point $z_{t}$ in $C$ satisfying $z_{t}=t u+(1-t) T z_{t}$ because the mapping $x \mapsto t u+(1-t) T x$ is contractive; see [2]. In 1967, Browder [5] proved the following strong convergence theorem.

Theorem 1 (Browder [5]). Let $C$ be a bounded closed convex subset of a Hilbert space $E$ and let $T$ be a nonexpansive mapping on $C$. Fix $u \in C$ and define $z_{t} \in C$ as $z_{t}=t u+(1-t) T z_{t}$ for $t \in(0,1)$. Then as t tends to $+0,\left\{z_{t}\right\}$ converges strongly to the element of $F(T)$ nearest to $u$.

Reich extended this theorem to uniformly smooth Banach spaces in [15. As motivated by Theorem 1] Halpern [1] considered the following explicit iteration:

$$
x_{n+1}=\alpha_{n} u+\left(1-\alpha_{n}\right) T x_{n}
$$

and proved the following.

Theorem 2 (Halpern [11]). Let E, C, T, u be as in Theorem 1. Define a real sequence $\left\{\alpha_{n}\right\}$ in $[0,1]$ by $\alpha_{n}=n^{-\theta}$, where $\theta \in(0,1)$. Define a sequence $\left\{x_{n}\right\}$ in $C$ by $x_{1} \in C$ and (11). Then $\left\{x_{n}\right\}$ converges strongly to the element of $F(T)$ nearest to $u$.

Received by the editors March 1, 2005 and, in revised form, July 18, 2005.

2000 Mathematics Subject Classification. Primary 47H09; Secondary 47H10.

Key words and phrases. Nonexpansive mapping, fixed point, Halpern-type strong convergence theorem.

The author was supported in part by Grants-in-Aid for Scientific Research from the Japanese Ministry of Education, Culture, Sports, Science and Technology.

(C)2006 American Mathematical Society Reverts to public domain 28 years from publication 
Lions [14] improved Theorem 2], In [14, our assumption is

(C1) $\lim _{n} \alpha_{n}=0$;

(C2) $\sum_{n=1}^{\infty} \alpha_{n}=\infty$;

(C3) $\lim _{n}\left(\alpha_{n+1}-\alpha_{n}\right) / \alpha_{n+1}^{2}=0$.

Several authors have studied condition (C3). Wittmann 23 proved a strong convergence theorem under the assumption of $(\mathrm{C} 1),(\mathrm{C} 2)$ and

(C4) $\sum_{n=1}^{\infty}\left|\alpha_{n+1}-\alpha_{n}\right|<\infty$.

$\mathrm{Xu}$ [24, 25] considered the conditions (C1), (C2) and

(C5) $\lim _{n}\left(\alpha_{n+1}-\alpha_{n}\right) / \alpha_{n+1}=0$.

Very recently, Cho, Kang and Zhou 9 considered (C1), (C2) and

(C6) $\left|\alpha_{n+1}-\alpha_{n}\right| \leq o\left(\alpha_{n+1}\right)+\sigma_{n}$ and $\sum_{n=1}^{\infty} \sigma_{n}<\infty$.

On the other hand, Shioji and Takahashi [17] proved a convergence theorem in Banach spaces under the assumption of (C1), (C2) and (C4). See also [8].

In this paper, we introduce a new explicit iteration similar to (11), and prove strong convergence theorems under the assumption of only $(\mathrm{C} 1)$ and $(\mathrm{C} 2)$. We also show that the conjunction of $(\mathrm{C} 1)$ and $(\mathrm{C} 2)$ is the necessary and sufficient condition on our iteration. This is a partial answer of Problem 6 in Reich [16].

\section{Preliminaries}

Throughout this paper, we denote by $\mathbb{N}$ the set of all positive integers.

Let $\left\{x_{n}\right\}$ be a sequence in a topological space $X$. By the Axiom of Choice, there exist a directed set $(D, \leq)$ and a universal subnet $\left\{x_{f(\nu)}: \nu \in D\right\}$ of $\left\{x_{n}\right\}$, i.e.,

(i) $f$ is a mapping from $D$ into $\mathbb{N}$ such that for each $n \in \mathbb{N}$ there exists $\nu_{0} \in D$ such that $\nu \geq \nu_{0}$ implies $f(\nu) \geq n$; and

(ii) for each subset $A$ of $X$, there exists $\nu_{0} \in D$ such that either $\left\{x_{f(\nu)}: \nu \geq\right.$ $\left.\nu_{0}\right\} \subset A$ or $\left\{x_{f(\nu)}: \nu \geq \nu_{0}\right\} \subset X \backslash A$ holds.

We know that if a net $\left\{x_{\nu}\right\}$ is universal and $g$ is a mapping from $X$ into an arbitrary set $Y$, then $\left\{g\left(x_{\nu}\right)\right\}$ is also universal. We also know that if $X$ is compact, then a universal net $\left\{x_{\nu}\right\}$ always converges. See [12] for details.

Let $E$ be a real Banach space. We denote by $E^{*}$ the dual of $E$. $E$ is said to be smooth or said to have a Gâteaux differentiable norm if the limit

$$
\lim _{t \rightarrow 0} \frac{\|x+t y\|-\|x\|}{t}
$$

exists for each $x, y \in E$ with $\|x\|=\|y\|=1$. $E$ is said to have a uniformly Gâteaux differentiable norm if for each $y \in E$ with $\|y\|=1$, the limit is attained uniformly in $x \in E$ with $\|x\|=1$. $E$ is said to be uniformly smooth or said to have a uniformly Fréchet differentiable norm if the limit is attained uniformly in $x, y \in E$ with $\|x\|=\|y\|=1$.

Let $E$ be a smooth Banach space. The duality mapping $J$ from $E$ into $E^{*}$ is defined as

$$
\langle x, J(x)\rangle=\|x\|^{2}=\|J(x)\|^{2}
$$

for all $x \in E$. We note that

$$
\|x+y\|^{2} \geq\|x\|^{2}+2\langle y, J(x)\rangle
$$

for all $x, y \in E$ because $J$ is the subdifferential of $x \mapsto \frac{1}{2}\|x\|^{2}$. We also note that when the norm of $E$ is uniformly Gâteaux differentiable, the duality mapping is 
uniformly continuous on bounded subsets of $E$ from the strong topology of $E$ into the weak* topology of $E^{*}$.

Let $C$ and $K$ be subsets of a Banach space $E$. A mapping $P$ from $C$ into $K$ is called sunny [6] if

$$
P(P x+t(x-P x))=P x
$$

for $x \in C$ with $P x+t(x-P x) \in C$ and $t \geq 0$.

The following is proved in [21]. See also [18, 20, 22].

Lemma 1 (21]). Let $\left\{x_{n}\right\}$ and $\left\{y_{n}\right\}$ be bounded sequences in a Banach space $E$ and let $\left\{\beta_{n}\right\}$ be a sequence in $[0,1]$ with $0<\liminf _{n} \beta_{n} \leq \lim \sup _{n} \beta_{n}<1$. Suppose that $x_{n+1}=\beta_{n} y_{n}+\left(1-\beta_{n}\right) x_{n}$ for all $n \in \mathbb{N}$ and

$$
\limsup _{n \rightarrow \infty}\left(\left\|y_{n+1}-y_{n}\right\|-\left\|x_{n+1}-x_{n}\right\|\right) \leq 0 .
$$

Then $\lim _{n}\left\|y_{n}-x_{n}\right\|=0$.

The following lemma is well known. For example, see Lemma 2.1 in 24].

Lemma 2. Let $\left\{\alpha_{n}\right\},\left\{\beta_{n}\right\}$ and $\left\{\gamma_{n}\right\}$ be nonnegative real sequences satisfying

$$
\sum_{n=1}^{\infty} \alpha_{n}=\infty, \quad \lim _{n \rightarrow \infty} \beta_{n}=0, \quad \alpha_{n} \leq 1, \quad \text { and } \quad \gamma_{n+1} \leq\left(1-\alpha_{n}\right) \gamma_{n}+\alpha_{n} \beta_{n}
$$

for $n \in \mathbb{N}$. Then $\left\{\gamma_{n}\right\}$ converges to 0 .

Bruck [7. essentially proved the following lemma. See also [19].

Lemma 3 (Bruck [7). Let $C$ be a closed convex subset of a strictly convex Banach space $E$. Let $\left\{T_{n}: n \in \mathbb{N}\right\}$ be a sequence of nonexpansive mappings on $C$. Suppose $\bigcap_{n=1}^{\infty} F\left(T_{n}\right)$ is nonempty. Let $\left\{\lambda_{n}\right\}$ be a sequence of positive numbers with $\sum_{n=1}^{\infty} \lambda_{n}=1$. Then a mapping $S$ on $C$ defined by

$$
S x=\sum_{n=1}^{\infty} \lambda_{n} T_{n} x
$$

for $x \in C$ is well defined, nonexpansive and $F(S)=\bigcap_{n=1}^{\infty} F\left(T_{n}\right)$ holds.

\section{SUFFICIENCY}

In this section, proving the following theorem, we show that the conjunction of $(\mathrm{C} 1)$ and $(\mathrm{C} 2)$ is a sufficient condition on our iteration.

Theorem 3. Let $E$ be a Banach space whose norm is uniformly Gâteaux differentiable and let $T$ be a nonexpansive mapping on a closed convex subset $C$ of $E$. Fix $u \in C$ and define a sequence $\left\{x_{n}\right\}$ in $C$ by $x_{1} \in C$ and

$$
x_{n+1}=\alpha_{n} u+\left(1-\alpha_{n}\right)\left(\lambda T x_{n}+(1-\lambda) x_{n}\right)
$$

for $n \in \mathbb{N}$, where $\lambda \in(0,1)$ and $\left\{\alpha_{n}\right\}$ is a sequence in $[0,1]$ with $(\mathrm{C} 1)$ and $(\mathrm{C} 2)$. Assume that $\left\{z_{t}\right\}$ converges strongly to some point $z \in C$ as $t$ tends to +0 , where $z_{t}$ is the unique element of $C$ with $z_{t}=t u+(1-t) T z_{t}$ for every $t \in(0,1)$. Then $\left\{x_{n}\right\}$ converges strongly to $z$.

Remark. It is obvious that $z$ is a fixed point of $T$. 
Proof. Put $M=\left\|x_{1}-z\right\|+\|u-z\|$ and

$$
y_{n}=\frac{\alpha_{n} u+\left(1-\alpha_{n}\right) \lambda T x_{n}}{\alpha_{n}+\left(1-\alpha_{n}\right) \lambda}
$$

for every $n \in \mathbb{N}$. Then we can write

$$
x_{n+1}=\left(\alpha_{n}+\left(1-\alpha_{n}\right) \lambda\right) y_{n}+\left(1-\alpha_{n}-\left(1-\alpha_{n}\right) \lambda\right) x_{n}
$$

for $n \in \mathbb{N}$. We note that

$$
\lim _{n \rightarrow \infty}\left(\alpha_{n}+\left(1-\alpha_{n}\right) \lambda\right)=\lambda \in(0,1) .
$$

$\left\|x_{1}-z\right\| \leq M$ is clear. Since

$$
\begin{aligned}
\left\|x_{n+1}-z\right\| & \leq \alpha_{n}\|u-z\|+\left(1-\alpha_{n}\right) \lambda\left\|T x_{n}-z\right\|+\left(1-\alpha_{n}\right)(1-\lambda)\left\|x_{n}-z\right\| \\
& \leq \alpha_{n}\|u-z\|+\left(1-\alpha_{n}\right) \lambda\left\|x_{n}-z\right\|+\left(1-\alpha_{n}\right)(1-\lambda)\left\|x_{n}-z\right\| \\
& =\alpha_{n}\|u-z\|+\left(1-\alpha_{n}\right)\left\|x_{n}-z\right\|
\end{aligned}
$$

for $n \in \mathbb{N}$, we have $\left\|x_{n}-z\right\| \leq M$ for all $n \in \mathbb{N}$ by induction. We also have

$$
\begin{aligned}
\left\|y_{n}-z\right\| & \leq \frac{\alpha_{n}\|u-z\|+\left(1-\alpha_{n}\right) \lambda\left\|T x_{n}-z\right\|}{\alpha_{n}+\left(1-\alpha_{n}\right) \lambda} \\
& \leq \frac{\alpha_{n}\|u-z\|+\left(1-\alpha_{n}\right) \lambda\left\|x_{n}-z\right\|}{\alpha_{n}+\left(1-\alpha_{n}\right) \lambda} \\
& \leq \frac{\alpha_{n} M+\left(1-\alpha_{n}\right) \lambda M}{\alpha_{n}+\left(1-\alpha_{n}\right) \lambda} \\
& =M<\infty .
\end{aligned}
$$

Hence, $\left\{x_{n}\right\}$ and $\left\{y_{n}\right\}$ are bounded sequences in $C$. Besides, we have

$$
\begin{aligned}
& \limsup _{n \rightarrow \infty}\left(\left\|y_{n+1}-y_{n}\right\|-\left\|x_{n+1}-x_{n}\right\|\right) \\
& =\limsup _{n \rightarrow \infty}\left(\left\|\frac{\alpha_{n+1} u+\left(1-\alpha_{n+1}\right) \lambda T x_{n+1}}{\alpha_{n+1}+\left(1-\alpha_{n+1}\right) \lambda}-\frac{\alpha_{n} u+\left(1-\alpha_{n}\right) \lambda T x_{n}}{\alpha_{n}+\left(1-\alpha_{n}\right) \lambda}\right\|\right. \\
& \left.-\left\|x_{n+1}-x_{n}\right\|\right) \\
& \leq \limsup _{n \rightarrow \infty}\left(\left|\frac{\alpha_{n+1}}{\alpha_{n+1}+\left(1-\alpha_{n+1}\right) \lambda}-\frac{\alpha_{n}}{\alpha_{n}+\left(1-\alpha_{n}\right) \lambda}\right|\|u\|\right. \\
& +\frac{\left(1-\alpha_{n+1}\right) \lambda}{\alpha_{n+1}+\left(1-\alpha_{n+1}\right) \lambda}\left\|T x_{n+1}-T x_{n}\right\| \\
& +\left|\frac{\left(1-\alpha_{n+1}\right) \lambda}{\alpha_{n+1}+\left(1-\alpha_{n+1}\right) \lambda}-\frac{\left(1-\alpha_{n}\right) \lambda}{\alpha_{n}+\left(1-\alpha_{n}\right) \lambda}\right|\left\|T x_{n}\right\| \\
& \left.-\left\|x_{n+1}-x_{n}\right\|\right) \\
& \leq \limsup _{n \rightarrow \infty}\left(\left|\frac{\alpha_{n+1}}{\alpha_{n+1}+\left(1-\alpha_{n+1}\right) \lambda}-\frac{\alpha_{n}}{\alpha_{n}+\left(1-\alpha_{n}\right) \lambda}\right|\|u\|\right. \\
& +\left(\frac{\left(1-\alpha_{n+1}\right) \lambda}{\alpha_{n+1}+\left(1-\alpha_{n+1}\right) \lambda}-1\right)\left\|x_{n+1}-x_{n}\right\| \\
& \left.+\left|\frac{\left(1-\alpha_{n+1}\right) \lambda}{\alpha_{n+1}+\left(1-\alpha_{n+1}\right) \lambda}-\frac{\left(1-\alpha_{n}\right) \lambda}{\alpha_{n}+\left(1-\alpha_{n}\right) \lambda}\right|(M+\|z\|)\right) \\
& =0 \text {. }
\end{aligned}
$$


Thus, by Lemma 1, we obtain $\lim _{n}\left\|y_{n}-x_{n}\right\|=0$. Therefore

$$
\lim _{n \rightarrow \infty}\left\|x_{n+1}-x_{n}\right\|=\lim _{n \rightarrow \infty}\left(\alpha_{n}+\left(1-\alpha_{n}\right) \lambda\right)\left\|y_{n}-x_{n}\right\|=0 .
$$

We next show

$$
\limsup _{n \rightarrow \infty}\left\langle u-z, J\left(x_{n}-z\right)\right\rangle \leq 0 .
$$

We choose a universal subnet $\left\{x_{f(\nu)}: \nu \in D\right\}$ of $\left\{x_{n}\right\}$ with

$$
\lim _{\nu \in D}\left\langle u-z, J\left(x_{f(\nu)}-z\right)\right\rangle=\limsup _{n \rightarrow \infty}\left\langle u-z, J\left(x_{n}-z\right)\right\rangle .
$$

Then we have

$$
\begin{aligned}
\left\|x_{n}-T z_{t}\right\| \leq & \left\|x_{n}-x_{n+1}\right\|+\left\|x_{n+1}-T z_{t}\right\| \\
\leq & \left\|x_{n}-x_{n+1}\right\|+\alpha_{n}\left\|u-T z_{t}\right\|+\left(1-\alpha_{n}\right) \lambda\left\|T x_{n}-T z_{t}\right\| \\
& +\left(1-\alpha_{n}\right)(1-\lambda)\left\|x_{n}-T z_{t}\right\| \\
\leq & \left\|x_{n}-x_{n+1}\right\|+\alpha_{n}\left\|u-T z_{t}\right\|+\left(1-\alpha_{n}\right) \lambda\left\|x_{n}-z_{t}\right\| \\
& +\left(1-\alpha_{n}\right)(1-\lambda)\left\|x_{n}-T z_{t}\right\|
\end{aligned}
$$

for $n \in \mathbb{N}$ and $t \in(0,1)$, and hence

$$
\lim _{\nu \in D}\left\|x_{f(\nu)}-T z_{t}\right\| \leq \lim _{\nu \in D}\left(\lambda\left\|x_{f(\nu)}-z_{t}\right\|+(1-\lambda)\left\|x_{f(\nu)}-T z_{t}\right\|\right)
$$

by (3). Thus we obtain

$$
\lim _{\nu \in D}\left\|x_{f(\nu)}-T z_{t}\right\| \leq \lim _{\nu \in D}\left\|x_{f(\nu)}-z_{t}\right\|
$$

for $t \in(0,1)$. From the definition of $\left\{z_{t}\right\}$, we have

$$
\begin{aligned}
& \lim _{\nu \in D}\left\|x_{f(\nu)}-z_{t}\right\|^{2} \\
& \geq \lim _{\nu \in D}\left\|x_{f(\nu)}-T z_{t}\right\|^{2} \\
& =\lim _{\nu \in D}\left\|\left(x_{f(\nu)}-z_{t}\right)+\frac{t}{1-t}\left(u-z_{t}\right)\right\|^{2} \\
& \geq \lim _{\nu \in D}\left(\left\|x_{f(\nu)}-z_{t}\right\|^{2}+\frac{2 t}{1-t}\left\langle u-z_{t}, J\left(x_{f(\nu)}-z_{t}\right)\right\rangle\right)
\end{aligned}
$$

for $t \in(0,1)$ and hence

$$
\lim _{\nu \in D}\left\langle u-z_{t}, J\left(x_{f(\nu)}-z_{t}\right)\right\rangle \leq 0 .
$$

We note that $\left\{\left\langle u-z_{t}, J\left(x_{n}-z_{t}\right)\right\rangle\right\}$ converges uniformly to $\left\langle u-z, J\left(x_{n}-z\right)\right\rangle$ as $t$ tends to +0 because the norm of $E$ is Gâteaux uniformly differentiable. Thus we obtain

$$
\lim _{\nu \in D}\left\langle u-z, J\left(x_{f(\nu)}-z\right)\right\rangle \leq 0
$$

This implies (44). Since $z$ is a fixed point of $T$, we have

$$
\begin{aligned}
\left(1-\alpha_{n}\right)\left\|x_{n}-z\right\|^{2} & \geq\left(1-\alpha_{n}\right)^{2}\left\|x_{n}-z\right\|^{2} \\
& \geq\left(1-\alpha_{n}\right)^{2}\left\|\lambda T x_{n}+(1-\lambda) x_{n}-z\right\|^{2} \\
& =\left\|\left(x_{n+1}-z\right)-\alpha_{n}(u-z)\right\|^{2} \\
& \geq\left\|x_{n+1}-z\right\|^{2}-2 \alpha_{n}\left\langle u-z, J\left(x_{n+1}-z\right)\right\rangle
\end{aligned}
$$


and hence

$$
\left\|x_{n+1}-z\right\|^{2} \leq\left(1-\alpha_{n}\right)\left\|x_{n}-z\right\|^{2}+\alpha_{n} \max \left\{0,2\left\langle u-z, J\left(x_{n+1}-z\right)\right\rangle\right\}
$$

for $n \in \mathbb{N}$. By Lemma 2 and (4), $\left\{x_{n}\right\}$ converges strongly to $z$. This completes the proof.

As direct consequences of Theorem 3, we obtain the following.

Corollary 1. Let $E$ be a uniformly smooth Banach space. Let $C, T, u, \lambda,\left\{\alpha_{n}\right\}$, $\left\{x_{n}\right\}$ be as in Theorem 3, Assume that $C$ is bounded. Then $\left\{x_{n}\right\}$ converges strongly to $P u$, where $P$ is the unique sunny nonexpansive retraction from $C$ onto $F(T)$.

Corollary 2. Let $E$ be a Hilbert space. Let $C, T, u, \lambda,\left\{\alpha_{n}\right\},\left\{x_{n}\right\}$ be as in Theorem 3. Assume that $C$ is bounded. Then $\left\{x_{n}\right\}$ converges strongly to the element of $F(T)$ nearest to $u$.

Using Theorem 3 and Lemma 3, we obtain the following.

Theorem 4. Let $E$ be a strictly convex Banach space whose norm is uniformly Gâteaux differentiable. Let $\left\{T_{n}: n \in \mathbb{N}\right\}$ be a sequence of nonexpansive mappings on a closed convex subset $C$ of $E$. Suppose that $\bigcap_{n=1}^{\infty} F\left(T_{n}\right)$ is nonempty. Define a nonexpansive mapping $S$ on $C$ by

$$
S x=\frac{1}{\lambda} \sum_{n=1}^{\infty} \lambda_{n} T_{n} x
$$

for $x \in C$, where $\left\{\lambda_{n}\right\}$ is a sequence of positive numbers with $\sum_{n=1}^{\infty} \lambda_{n}<1$ and $\lambda=\sum_{n=1}^{\infty} \lambda_{n}$. Fix $u \in C$ and define a sequence $\left\{x_{n}\right\}$ in $C$ by $x_{1} \in C$ and

$$
x_{n+1}=\alpha_{n} u+\left(1-\alpha_{n}\right)\left(\lambda S x_{n}+(1-\lambda) x_{n}\right)
$$

for $n \in \mathbb{N}$, where $\left\{\alpha_{n}\right\}$ is a sequence in $[0,1]$ with $(\mathrm{C} 1)$ and $(\mathrm{C} 2)$. Assume that $\left\{z_{t}\right\}$ converges strongly to some point $z \in C$ as $t$ tends to +0 , where $z_{t}$ is the unique element of $C$ with $z_{t}=t u+(1-t) S z_{t}$ for every $t \in(0,1)$. Then $\left\{x_{n}\right\}$ converges strongly to $z$.

Remark. (i) The assumption of $\bigcap_{n=1}^{\infty} F\left(T_{n}\right) \neq \varnothing$ is needed.

(ii) It is obvious that $z$ is a common fixed point of $\left\{T_{n}: n \in \mathbb{N}\right\}$ by Lemma 3

\section{NECESSITY}

In this section, we show that the conjunction of $(\mathrm{C} 1)$ and $(\mathrm{C} 2)$ is a necessary condition on our iteration. That is, the conjunction of $(\mathrm{C} 1)$ and $(\mathrm{C} 2)$ is the sufficient and necessary condition. We note that the proof of Theorem 2 in Halpern [11] is not valid in our discussion.

Example 1. Let $E$ be the two-dimensional real Hilbert space and put a bounded closed convex subset $C$ of $E$ by

$$
C=\left\{x \in E: x(1) \geq 0, x(2) \geq 0, x(1)^{2}+x(2)^{2} \leq 1\right\} .
$$

Define a nonexpansive mapping $T$ on $C$ by

$$
T x=\left(0, \sqrt{x(1)^{2}+x(2)^{2}}\right)
$$

for all $x \in C$. Let $\left\{\alpha_{n}\right\}$ be a real sequence in $[0,1]$, let $\lambda \in(0,1)$ and put $u=(1,0)$. Define $\left\{x_{n}\right\}$ in $C$ by $x_{1}=u$ and (2), and assume $\left\{x_{n}\right\}$ converges to $(0,0)$. Then $\left\{\alpha_{n}\right\}$ satisfies $(\mathrm{C} 1)$ and $(\mathrm{C} 2)$. 
Proof. We first note that the element of $F(T)$ nearest to $u$ is $(0,0)$. We have

$$
x_{n+1}=\left[\begin{array}{c}
\alpha_{n}+\left(1-\alpha_{n}\right)(1-\lambda) x_{n}(1) \\
\left(1-\alpha_{n}\right) \lambda \sqrt{x_{n}(1)^{2}+x_{n}(2)^{2}}+\left(1-\alpha_{n}\right)(1-\lambda) x_{n}(2)
\end{array}\right]
$$

for $n \in \mathbb{N}$. By induction, we can show $x_{n} \neq(0,0)$ for all $n \in \mathbb{N}$. Since $x_{n+1}(1) \geq \alpha_{n}$ for $n \in \mathbb{N}$ and $\lim _{n} x_{n}(1)=0,\left\{\alpha_{n}\right\}$ satisfies (C1). So we can choose $\ell \in \mathbb{N}$ satisfying $\alpha_{n}<1$ for all $n \geq \ell$. Then we note $x_{\ell+1}(2)>0$. Since $x_{n+1}(2) \geq\left(1-\alpha_{n}\right) x_{n}(2)$ for $n \in \mathbb{N}$, we have $x_{n}(2) \geq\left(\prod_{k=\ell+1}^{n-1}\left(1-\alpha_{k}\right)\right) x_{\ell+1}(2)$ for all $n>\ell+1$. Since $\lim _{n} x_{n}(2)=0$, we obtain $\prod_{k=\ell+1}^{n-1}\left(1-\alpha_{k}\right)=0$. Thus, $\left\{\alpha_{n}\right\}$ satisfies (C2).

Therefore we have shown the following.

Proposition 1. Let $\left\{\alpha_{n}\right\}$ be a real sequence in $[0,1]$. Then the following are equivalent:

(i) $\left\{\alpha_{n}\right\}$ satisfies $(\mathrm{C} 1)$ and $(\mathrm{C} 2)$.

(ii) If $T$ is a nonexpansive mapping on a bounded closed convex subset $C$ of a Hilbert space $E, u \in C, \lambda \in(0,1)$, and $\left\{x_{n}\right\}$ is a sequence in $C$ defined by $x_{1} \in C$ and (2), then $\left\{x_{n}\right\}$ converges strongly to the element of $F(T)$ nearest to $u$.

Remark. This is a partial answer of Problem 6 in Reich [16 because for $\lambda \in(0,1)$ and a nonexpansive mapping $T$, a mapping $x \mapsto \lambda T x+(1-\lambda) x$ is nonexpansive, and the two sets of fixed points of such mapping and $T$ coincide.

\section{REFERENCES}

[1] J. B. Baillon, "Quelques aspects de la théorie des points fixes dans les espaces de Banach. I, II." (in French), Séminaire d'Analyse Fonctionnelle (1978-1979), Exp. No. 7-8, 45 pp., École Polytech., Palaiseau, 1979. MR0557363 (81d:47036)

[2] S. Banach, "Sur les opérations dans les ensembles abstraits et leur application aux équations intégrales", Fund. Math., 3 (1922), 133-181.

[3] F. E. Browder, "Fixed-point theorems for noncompact mappings in Hilbert space", Proc. Nat. Acad. Sci. USA, 53 (1965), 1272-1276. MR0178324 (31:2582)

[4] F. E. Browder, "Nonexpansive nonlinear operators in a Banach space", Proc. Nat. Acad. Sci. USA, 54 (1965), 1041-1044. MR0187120 (32:4574)

[5] F. E. Browder, "Convergence of approximants to fixed points of nonexpansive nonlinear mappings in Banach spaces", Arch. Ration. Mech. Anal., 24 (1967), 82-90. MR0206765 $(34: 6582)$

[6] R. E. Bruck, "Nonexpansive retracts of Banach spaces", Bull. Amer. Math. Soc., 76 (1970), 384-386. MR0256135 (41:794)

[7] R. E. Bruck, "Properties of fixed-point sets of nonexpansive mappings in Banach spaces", Trans. Amer. Math. Soc., 179 (1973), 251-262. MR0324491 (48:2843)

[8] C. E. Chidume, J. Li and A. Udomene, "Convergence of paths and approximation of fixed points of asymptotically nonexpansive mappings", Proc. Amer. Math. Soc., 133 (2005), 473480. MR2093070 (2005f:47122)

[9] Y. J. Cho, S. M. Kang and H. Y. Zhou, "Some control conditions on the iterative methods", to appear in Internat. J. Comput. Numer. Anal. Appl.

[10] D. Göhde, "Zum Prinzip def kontraktiven Abbildung", Math. Nachr., 30 (1965), 251-258. MR0190718 (32:8129)

[11] B. Halpern, "Fixed points of nonexpanding maps", Bull. Amer. Math. Soc., 73 (1967), 957961. MR0218938 (36:2022)

[12] J. L. Kelley, "General Topology", Van Nostrand Reinhold Company (1955). MR0070144 $(16: 1136 \mathrm{c})$

[13] W. A. Kirk, "A fixed point theorem for mappings which do not increase distances", Amer. Math. Monthly, 72 (1965), 1004-1006. MR0189009 (32:6436) 
[14] P.-L. Lions, "Approximation de points fixes de contractions", C. R. Acad. Sci. Paris Ser. A-B 284 (1977), A1357-A1359. MR0470770 (57:10515)

[15] S. Reich, "Strong convergence theorems for resolvents of accretive operators in Banach spaces", J. Math. Anal. Appl., 75 (1980), 287-292. MR0576291(82a:47050)

[16] S. Reich, "Some problems and results in fixed point theory", Contemp. Math., 21 (1983), 179-187. MR0729515 (85e:47082)

[17] N. Shioji and W. Takahashi, "Strong convergence of approximated sequences for nonexpansive mappings in Banach spaces", Proc. Amer. Math. Soc., 125 (1997), 3641-3645. MR1415370 (98e:47088)

[18] T. Suzuki, "Strong convergence theorem to common fixed points of two nonexpansive mappings in general Banach spaces", J. Nonlinear Convex Anal., 3 (2002), 381-391. MR.1947106 (2003i:47066)

[19] T. Suzuki, "Convergence theorems to common fixed points for infinite families of nonexpansive mappings in strictly convex Banach spaces", Nihonkai Math. J., 14 (2003), 43-54. MR1986983 (2004d:47089)

[20] T. Suzuki, "Krasnoselskii and Mann's type sequences and Ishikawa's strong convergence theorem", in Proceedings of the Third International Conference on Nonlinear Analysis and Convex Analysis (W. Takahashi and T. Tanaka Eds.), pp. 527-539, Yokohama Publishers, 2004. MR2144072 (2006b:47107)

[21] T. Suzuki, "Strong convergence theorems for infinite families of nonexpansive mappings in general Banach spaces", Fixed Point Theory Appl., 2005 (2005), 103-123. MR2172156

[22] T. Suzuki, "Strong convergence of Krasnoselskii and Mann's type sequences for oneparameter nonexpansive semigroups without Bochner integrals", J. Math. Anal. Appl., 305 (2005), 227-239. MR2128124 (2005j:47055)

[23] R. Wittmann, "Approximation of fixed points of nonexpansive mappings", Arch. Math. (Basel), 58 (1992), 486-491. MR 1156581 (93c:47069)

[24] H. K. Xu, "Another control condition in an iterative method for nonexpansive mappings", Bull. Austral. Math. Soc., 65 (2002), 109-113. MR1889384(2002m:47076)

[25] H. K. Xu, "Iterative algorithms for nonlinear operators", J. London Math. Soc., 66 (2002), 240-256. MR 1911872(2003e:47114)

Department of Mathematics, Kyushu Institute of Technology, Sensuicho, Tobata, KiTAKYUSHU 804-8550, JAPAN

E-mail address: suzuki-t@mns.kyutech.ac.jp 